\title{
The Prosodic Structure of Function Words
}

\author{
Elisabeth Selkirk \\ University of Massachusetts/Amherst
}

\section{Introduction 1}

It seems likely that all languages make a distinction between words belonging to functional categories and those belonging to lexical categories, a distinction which roughly coincides with the sets of open and closed class items. Nouns, verbs and adjectives constitute the class of lexical categories in English, while determiners, prepositions, auxiliaries, modals, complementizers, conjunctions and other sorts of particles fall into the class of functional categories. The distinction between lexical and functional categories plays an important role in characterizing the syntactic properties of sentences (Jackendoff 1977, Chomsky 1986, Fukui and Speas 1986, Abney 1987, Pollock 1989, Grimshaw 1991). Now it happens that words belonging to functional categories display phonological properties significantly different from those of words belonging to lexical categories (Selkirk 1972, 1984, 1986, Kaisse 1985, Berendson 1986, Nespor and

\footnotetext{
$1 \quad$ The research for this paper was carried out in part with the support of NSF grant BNS-86-17827. This paper is a slightly revised version of a paper appearing in Signal to Syntax, ed. by K. Demuth and J. Morgan, Lawrence Erlbaum, 1995. Both these versions involve a substantial revision of an earlier 1993 manuscript which circulated under the same title. Earlier versions of the paper were presented in the Fall 1992 Phonology Proseminar at UMass, at the conference Signal to Syntax held at Brown in February 1993, at talks the University of Tuebingen and the University of Konstanz in summer 1993 and at the First Rutgers Optimality Workshop held in October 1993. I want to thank the participants for their comments. I also want to particularly thank Geert Booij, Pat Deevy,
} 
Vogel 1986, Kanerva 1989, Inkelas 1989, Zec 1993). For example, in English, monosyllabic function words may appear in either a stressless 'weak' form or a stressed 'strong' form, depending on their

position in the sentence, whereas a lexical category word always appears in a stressed unreduced form. In standard Serbo-Croatian, a lexical word always bears a high tone accent on one of its syllables, whereas a function word does not. In Tokyo Japanese, a function word will lose its high tone accent if it is preceded by another accented word in the same phrase, but in the same circumstances a lexical word will not lose its accent. The mere fact of a systematic phonological difference between words belonging to lexical and functional categories raises the possibility that this distinction might be exploited by the language learner in their acquisition of the syntactic distinction betwen lexical and functional categories, where what needs to learned as the first order of business is which words are functional and which lexical. The aim of this paper is to lay out the elements of a theory that will provide some insight into the lexical/functional contrast in phonology. Such a theory can provide a framework for discussion of a possible relation between the learning of the phonology of the functional/lexical distinction in a language and the acquisition of syntax in this domain.

A phrase consisting of a sequence of lexical words $(\text { Lex })^{2}$ in morphosyntactic representation ( $\mathrm{S}$-structure) is characteristically prosodized as a sequence of prosodic words $(\mathrm{PWd})$ in phonological representation (P-structure):

\footnotetext{
Katherine Demuth, Elan Dresher, Caroline Féry, Junko Itô, Angelika Kratzer, Aditi Lahiri, John McCarthy, Armin Mester, James Morgan, Sharon Peperkamp, Draga Zec and Katya Zubritskaya for further comments and discussion. 2 The X-bar theory of phrase structure (Jackendoff 1977) is assumed in this paper. The theory distinguishes three levels of morphosyntactic category: word, designated by X, or simply X; maximal projection, designated by $\mathrm{X}^{\mathrm{max}}$; and intermediary projections, designated by $\mathrm{X}^{\prime}$. Lex designates a morphosyntactic word belonging to a lexical category, i.e. N, V, or A. Fnc designates a morphosyntactic word belonging to a functional category.
} 

(1)
S-structure
[ Lex Lex ]
P-structure
$\left((\text { lex })_{\mathrm{PWd}}(\text { lex })_{\mathrm{PWd}}\right)_{\mathrm{PPh}}$

(Italicized lex stands for the phonological content of Lex.) The PWd structure of phrases with function words, by contrast, is more various. In this paper evidence will be presented that a function word (Fnc) may be prosodized either as a PWd, or as one of three different types of prosodic clitic. The term prosodic clitic will be taken to stand for a morphosyntactic word which is not itself a PWd. It will be argued that options in the surface prosodization of function words simply reflect the manner in which function words are organized into prosodic words in the sentence (see Berendsen 1986, Selkirk 1986, Zec 1988, 1993, Inkelas 1989, Kanerva 1989 who also argue for this position). Corresponding to a syntactic phrase [ Fnc Lex ], for example, four different organizations into prosodic word are in principle available ${ }^{3}$ :

$\begin{array}{llll}\text { S-structure } & & {[\text { Fnc Lex }]} & \\ \text { P-structure } & \text { (i) } & \left((\text { fnc })_{\mathrm{PWd}}(\text { lex })_{\mathrm{PWd}}\right)_{\mathrm{PPh}} & \text { Prosodic Word } \\ & & & \text { Prosodic Clitics: } \\ & \text { (ii) } & \left(\text { fnc }(\text { lex })_{\mathrm{PWd}}\right)_{\mathrm{PPh}} & \text { free clitic } \\ & \text { (iii) } & \left((\text { fnc lex })_{\mathrm{PWd}}\right)_{\mathrm{PPh}} & \text { internal clitic } \\ & \text { (iv) } & \left(\left(\text { fnc }(\text { lex })_{\mathrm{PWd}}\right)_{\mathrm{PWd}}\right)_{\mathrm{PPh}} & \text { affixal clitic }\end{array}$

(Italicized fnc stand for the phonological content of Fnc.) In (ii), the free clitic case, the function word is sister to PWd and daughter to phonological phrase (PPh). In (iii), where the function word is an internal clitic, it is dominated by the

3 Berendsen 1986 sorts weak, clitic, function words into those incorporated into an adjacent prosodic word, type (iii) here, and those immediately dominated by a phonological phrase, type (ii) here. Neyt 1985 argues for the recursive PWd type in (iv) as a candidate structure. The Zec 1993 proposal for Serbo-Croatian presuppose all three possibilities, see below. 
same PWd that dominates its sister lexical word. In the affixal clitic case, (iv), the function word is located in a nested PWd structure, both sister to PWd and dominated by PWd. The claim is that these and only these prosodic structures for function word are motivated by the facts of the two languages to be examined here-- English and Serbo-Croatian ${ }^{4}$.

A goal of this paper is to explain why it is that function words appear in this array of prosodic structures, and under what circumstances. I will argue that whether a function word in a particular syntactic configuration in a particular language is a prosodic word or not, and if not, what type of prosodic clitic it is, depends crucially on the interaction of various well-attested types of constraints on prosodic structure. That diverse families of constraints-- both morphosyntactic and phonological-- contribute to defining the prosodic organization of function words lends support to the modular theory of prosodic structure expounded in work by Selkirk 1989, 1993, Selkirk and Tateishi 1988, 1991, Selkirk and Shen 1990, Prince and Smolensky 1993 and McCarthy and Prince 1993ab. That an appeal to constraint interaction bears considerable fruit in this area lends support to optimality theory (Prince and Smolensky 1993, McCarthy and Prince 1993ab), which holds that the relative ranking of constraints constitutes a central aspect of grammatical description.

4 The claim implicit here is that accounting for the special phonological behavior does not require the postulation of a further prosodic constituent clitic group (contra Nespor and Vogel 1986, Vogel 1988, Hayes 1989, Nespor 1993). Rather the contention is that 'prosodic clitic' is definable with respect to the category prosodic word. More specifically, it is that prosodic clitics fall into one of three configurations, namely the free, internal or affixal clitic structures, all distinguishable in terms of domination and sisterhood relations defined with respect to PWd. To defend the clitic group hypothesis it must be shown that there exist relevant phenomena which cannot be insightfully accounted for by assuming one of these three PWd-based structures for prosodic clitics. 


\title{
1.1 Constraints on Prosodic Structure Prosodic structure theory holds that a
}

sentence is endowed with a hierarchically organized prosodic structure that is distinct from the morphosyntactic structure of the sentence and that phenomena of sentence phonology and phonetics are defined in terms of units of prosodic structure, not morphosyntactic structure ${ }^{5}$. According to prosodic structure theory, in any language sentences are organized into a structure whose categories are drawn from the set defined in the Prosodic Hierarchy:

\section{(3) The Prosodic Hierarchy (Selkirk 1978)}

\author{
Utt Utterance \\ IP intonational phrase \\ $\mathrm{PhP}$ phonological phrase \\ PWd prosodic word \\ $\mathrm{Ft} \quad$ foot \\ $\sigma \quad$ syllable
}

5 Works which argue for prosodic structure theory as a basis for a theory of sentence phonology include Selkirk 1978, 1981, 1986, 1989, Nespor and Vogel 1982, 1986, Booij 1983, Berendsen 1986, Beckman and Pierrehumbert 1986, Ladd 1986, Chen 1987, Hale and Selkirk 1987, Hyman 1987, 1988, 1990, Myers 1987, Rice 1987, Pierrehumbert and Beckman 1988, Hyman 1988, Selkirk and Tateishi 1988, 1991, Zec 1988, Bickmore 1989, Féry 1989,1993, Hayes 1989a [1984], Inkeles 1989, Kanerva 1989, Inkeles and Zec 1991, eds., and articles therein, McHugh 1990, Selkirk and Shen 1990, Kidima 1991, Kang 1992ab, Ladd 1992.

6 The Selkirk 1978 version of the Prosodic Hierarchy countenanced just one level of phonological phrase, $\mathrm{PPh}$, between Prosodic Word and Intonational Phrase. Nespor and Vogel 1986 hold to this position. But subsequent work has indicated that a larger variety of phrase types may be motivated. Selkirk 1986, 1989, 1993 as well as Selkirk and Tateishi (1988) crucially distinguish a Major Phrase and a Minor Phrase. Beckman and Pierrehumbert 1986, Pierrehumbert and Beckman 1988 distinguish two as well, dubbed the accentual phrase and the intermediate phrase. The question of how many levels of phrasing there are in the universal Prosodic Hierarchy turns out not to be relevant to the prosodic analysis of function words, however, and so has been ignored in the exposition in this paper. As for the prosodic category Clitic Group, posited by Nespor and Vogel 1986 and Hayes 1989, its exclusion is a principled one. There is arguably no such entity. (See footnote 4). 
This hierarchy of prosodic categories forms the core of the theory of phonological constraints on prosodic structure. It is in terms of this hierarchy that certain fundamental constraints on prosodic structure are defined:

\section{(4) Constraints on Prosodic Domination}

(where $\mathrm{C}^{\mathrm{n}}=$ some prosodic category)

(i) Layeredness No $\mathrm{C}^{\mathrm{i}}$ dominates a $\mathrm{C}^{\mathrm{j}}, \mathrm{j}>\mathrm{i}$,

e.g. "No $\sigma$ dominates a Ft."

(ii) Headedness Any $\mathrm{C}^{\mathrm{i}}$ must dominate a $\mathrm{C}^{\mathrm{i}-1}\left(\right.$ except if $\left.\mathrm{C}^{\mathrm{i}}=\sigma\right)$, e.g. "A PWd must dominate a Ft."

(iii) Exhaustivity No $\mathrm{C}^{\mathrm{i}}$ immediately dominates a constituent $\mathrm{C}^{\mathrm{j}}, \mathrm{j}<\mathrm{i}-1$, e.g. "No PWd immediately dominates a $\sigma . "$

(iv) Nonrecursivity No $\mathrm{C}^{\mathrm{i}}$ dominates $\mathrm{C}^{\mathrm{j}}, \mathrm{j}=\mathrm{i}$, e.g. "No Ft dominates a Ft."

For ease of reference I will call these constraints on prosodic domination.

According to the Strict Layer Hypothesis (Selkirk 1981, 1984, Nespor and Vogel 1986) these constraints on prosodic domination universally characterize prosodic structure. Expressed as a monolithic whole, the Strict Layer Hypothesis reads as a single constraint requiring that a prosodic constituent of level $\mathrm{C}^{\mathrm{i}}$ 
immediately dominate only constituents of the next level down in the prosodic hierarchy, $\mathrm{C}^{\mathrm{i}-1}$. That the Strict Layer Hypothesis should instead be factored out into more primitive component constraints, each with an independent status in the grammar, is argued by Inkelas 1989 and Ito and Mester 1992. The set of constraints on prosodic domination given above constitutes just such a decomposition of the Strict Layering.

Layeredness and Headedness, which together embody the essence of the Strict Layer Hypothesis, appear to be properties that hold universally, in all phonological representations. In optimality theoretic terms the inviolability of these constraints implies that they are undominated in the constraint ranking of every language. Exhaustivity and Nonrecursivity, on the other hand, turn out not to hold of all instances of P-structure. For example, it has been widely observed that there exist cases where a syllable is immediately dominated by a prosodic word, in violation of Exhaustivity (see, e.g. Inkelas 1989, Kanerva 1989, Hayes 1991, McCarthy and Prince 1991, 1993ab, Ito and Mester 1992, Kager 1993, Mester 1993, Prince and Smolensky 1993). The inviolability of Nonrecursivity has been challenged as well (Ladd 1986, 1992, Inkelas 1989, McCarthy and Prince 1993ab). Below we will see additional evidence in favor of viewing Nonrecursivity and Exhaustivity as constraints on prosodic structure that may be violated. In particular, free clitics (cf. (2-ii)) violate Exhaustivity-with-respect-toPhonological Phrase $\left(\operatorname{Exh}_{\mathrm{PPh}}\right)$ and affixal clitics (cf. (2-iv)) violate Nonrecursivitywith-respect-to-Prosodic Word (NonRec $\mathrm{PWd}_{\mathrm{P}}$ ), and Exhaustivity-with-respect-toProsodic Word $\left(\mathrm{Exh}_{\mathrm{PWd}}\right)$ as well. 
The class of constraints on prosodic domination constitute one, central, class of constraints on prosodic structure. Another significant class is constituted by constraints on alignment of edges of constituents (Selkirk 1986 et seq., McCarthy and Prince 1993ab). Selkirk 1986 et seq. argues that the relation between syntactic structure and prosodic structure is to be captured by constraints on the alignment of the two structures, ones which require that, for any constituent of category $\alpha$ in syntactic structure, its R (or L) edge coincides with the edge of a constituent of category $\beta$ in prosodic structure:

(5) The edge-based theory of the syntax-prosody interface (Selkirk 1986 et seq.)

Right/Left edge of $\alpha===>$ edge of $\beta$, $\alpha$ is a syntactic category, $\beta$ is a prosodic category

Edge-alignment constraints of this type have been shown to allow an insightful characterization of the influence of sentential phrase structure on prosodic structure in a wide array of languages (see many of the references in footnote 5), and have been argued to play a role in characterizing the influence of wordinternal structure on prosodic structure as well (see, e.g. Myers 1987, Cohn 1989, Rice 1991, Kang 1992ab, and McCarthy and Prince 1993ab). In recent work, McCarthy and Prince 1993ab have argued that the notion of edge alignment should be generalized; they show that a remarkable range of phonological phenomena yield to analysis in terms not only of constraints on grammatical structure-prosodic structure alignment but also in terms of constraints on the 
alignment of edges of various sorts of prosodic entities within phonological representation. The class of alignment constraints is enlarged to include constraints of the following general types:

(6) Generalized alignment (McCarthy \& Prince 1993b):

$$
\text { Align ( } \alpha \text { Cat, E; } \beta C a t, E)
$$

a. $\quad$ Align (GCat, E; PCat, E)

b. $\quad$ Align (PCat, E; GCat, E)

c. Align (PCat, E; PCat, E)

(GCat ranges over morphological and syntactic categories;

PCat ranges over the prosodic categories; E = Right or Left.)

These all state: "For any $\alpha$ Cat in the representation, align its edge $(\mathrm{R}, \mathrm{L})$ with the edge (R,L) of some $\beta$ Cat." We will see that alignment constraints of the various subclasses defined here arguably play a role in the characterization of the prosodic structure of function words.

Central to our concerns in this paper, then, is the alignment of words in morphosyntactic representation with the prosodic words of phonological representation. It is here that the morphosyntactic distinction between function 
words and lexical words comes into play. My proposal, one which echoes the position taken in Selkirk 1984, 1986 and Selkirk and Shen 1990, is that the set of constraints governing the interface between morphosyntactic and prosodic structure makes no reference to functional categories at all. Rather, it is only lexical categories and their phrasal projections which would figure in the statement of morphosyntactic constraints on prosodic structure; GCat would stand only for 'LexCat' in any constraint of the Align (GCat;PCat variety). The proposed form of the constraints which align grammatical words with prosodic words is accordingly as in (7):

\section{The Word Alignment Constraints (WdCon)}

$$
\text { Align (Lex, L; PWd, L) }
$$

(ii) $\quad$ Align (Lex, R; PWd, R)

$$
(=\mathrm{WdConL})
$$

$$
(=\mathrm{WdConR})
$$

We will see that it is the restriction of word alignment constraints to lexical category words that is responsible for the availability of prosodic clitic analyses for function words.

The generalized alignment theory also sanctions word-level alignment constraints of the Align (PCat; GCat) type in (8), where the category types are reversed: 
(i) Align (PWd, L; Lex, L)

(ii) Align (PWd, R; Lex, R)
$(=\mathrm{PWdConL})$

$(=\mathrm{PWdConR})$

The PWdCon constraints say that, for any PWd in the representation, its $\mathrm{L}$ (or R) edge must coincide with the $\mathrm{L}$ (or $\mathrm{R}$ ) edge of some Lex. A representation in which both were respected would contain no function word which itself had the status of a prosodic word. Thus, the PWdCon constraints form part of the explanation for the fact that function words typically do not have the status of PWd.

Summarizing briefly, the analysis of function word prosodization to be offered in what follows gives crucial roles to constraints on prosodic structure from two well-known families: constraints on prosodic domination such as Exhausitivity and Nonrecursivity and constraints on the alignment of prosodic structure and morphosyntactic structure such as WdCon and PWdCon. We will see that the precise manner in which these constraints are ranked in the grammar of a particular language provides the basis for explaining which of the variety of function word prosodizations is realized in a particular morphosyntactic configuration in that language.

\subsection{Constraint Ranking and Optimality Theory Optimality theory (Prince and} Smolensky 1993, McCarthy and Prince 1993a) understands the phonological component of a language to consist of a set of constraints on surface phonological 
representation. The grammatical output representation corresponding to a particular underlying input representation is that representation (out of all the candidate representations generable on the basis of that input) which best-satisfies the constraint system of the language. Constraints on representation are assumed to be violable. The violability of a constraint is hypothesized to be a function of the ranking of the constraint with respect to other constraints. The grammar of a language will stipulate a ranking of constraints. Thus a grammatical output representation is not necessarily well-formed with respect to all the relevant constraints, rather it is the best-formed, or optimal, representation evaluated with respect to the other candidate representations that are generable on the basis of the input.

Optimality theory assumes the constraints at play in grammars to be universal (with certain limited parameterizations available). Differences between languages or dialects are claimed to be reduceable to language-particular differences in the ranking of the constraints. The task of a language-learner, then, is to learn the constraint hierarchy of a particular language, the substance of the constraints being universally given. Tesar and Smolensky 1993 demonstrate that the learning of a constraint hierarchy is in principle an entirely tractable enterprise.

\subsection{Weak and Strong Forms of Function Words in English}


In English, a large number of the monosyllabic function words-prepositions, determiners, complementizers, auxiliary verbs, personal pronouns-may appear in either a 'weak', i.e. stressless and reduced, or a 'strong', i.e. stressed and unreduced, form (Sweet 1891, 1908, Jones 1964, Gimson 1970, Zwicky 1970, Selkirk 1972, 1984, Kaisse 1985, Berendsen 1986). This simple fact presents a challenge to any theory of syntax-phonology interaction: it needs to be explained why, in the same language, function words appear with different surface prosodizations. What I want to show is that these different surface prosodizations result from different underlying input structures, and that one and the same English-particular ranking of constraints is responsible for deriving the variety of surface prosodic structures attested.

Pronounced in isolation, function words appear in strong form and are indistinguishable stress-wise and vowel quality-wise from monosyllabic lexical category items:

\begin{tabular}{|c|c|c|}
\hline for & [før] & four \\
\hline can & [kæn] & (tin) can \\
\hline at & [æt] & hat \\
\hline would & {$\left[w^{\prime \prime} d\right]$} & wood \\
\hline that & {$[\partial æ t]$} & thatch \\
\hline him & [h^m] & hymn \\
\hline has & [hæz] & jazz \\
\hline is & {$\left[{ }^{\wedge} \mathrm{z}\right]$} & fizz \\
\hline
\end{tabular}


Strong forms also appear when the function word is focussed (see 2.1), and when it is phrase-final (see 2.4). Weak forms appear when the function word is nonfocussed and not phrase-final (see 2.3), and also when phrase-final but object of a verb or preposition (see 2.5). In their weak form(s), illustrated in (10), monosyllabic Fnc words display the properties of stressless syllables: vowel reduction, appearance of syllabic sonorants, loss of onset $h$, etc ${ }^{7}$.

$$
\begin{aligned}
& \text { f } \bullet 0^{\circ} \mathrm{r}[\mathrm{fr}] \quad \text { for Timothy (cf. fertility) } \\
& \mathrm{ca}^{\circ} \mathrm{n} \quad[\mathrm{kæn}],[\mathrm{kn} \leq],[\mathrm{km} \leq] \quad \text { can pile } \quad \text { (cf. compile) } \\
& \text { hi }{ }^{\circ} \mathrm{m} \quad[\text { hîm }],[\mathrm{m} \leq] \quad \text { need him } \quad \text { (cf. Needham) } \\
& \begin{array}{llll}
\mathrm{a}^{\circ} \mathrm{t} & {[\mathrm{t}]} & \text { at home } & \text { (cf. atone) }
\end{array}
\end{aligned}
$$

Prosodic theory analyzes stressed syllables as the prominent, or only, syllable of the prosodic constituent foot. Thus, the strong forms of monosyllabic function words in English have the status of a head of a foot and the weak forms do not. We will see that the foot-head status of strong forms is in most instances the consequence of the assignment of Prosodic Word status to the Fnc. Weak forms, by contrast, are prosodic clitics.

2.1 Focussed Fnc When focussed, a function word always appears in strong form:

$7 \quad$ Not all monosyllabic function words are able to appear in weak form, e.g. up, too, off, etc. I will assume that those which do alternate betweem weak and strong forms receive foot status as a result of constraints on surface representation. Invariably strong formed function words I will assume are already footed in the input to the phonological component. Which implies there is no defooting possible. 
(11) She spoke AT the microphone not WITH it.

Bettina CAN speak, but refuses to.

We need HER, not HIM.

It is a fact that, whether a Fnc or a Lex, a focussed word is assigned a pitch accent in the morphosyntactic structure of the sentence in English (cf. Pierrehumbert 1980, Selkirk 1984, Ch. 5). The presence of that pitch accent is arguably responsible for the strong form of focussed Fnc. It has been widely observed that pitch accents in English are associated only with stressed syllables (Liberman 1975, Ladd 1980, Pierrehumbert 1980, Selkirk 1984, Hayes 1991, Pierrehumbert 1993).

(12) Association of Pitch Accent (AssocPA)

A pitch accent associates to (aligns with) a stressed syllable (i.e. the head of a foot).

Such a constraint guarantees that the pitch accent which is assigned to a word in morphosyntactic representation will never be realized on a stressless syllable in prosodic structure, and thus rules out *ASSign, *strucTURE, *PROsodic, *foCUS. Compare the grammatical forms asSIGN, STRUCture, proSODic, FOCus, which respect this constraint. This same constraint allows us to explain why the morphosyntactic assignment of a pitch accent to a monosyllabic function word 
entails the strong form foot-head status of $f n c$ in P-structure. For a syllable to carry stress it must be the head of a Foot. Thus the presence of pitch accent in the input structure in effect induces the presence of the prosodic structure required in order for the constraint AssocPA to be satisfied in English:

$$
\text { [can }]_{\mathrm{Mod}}===>(\text { can })_{\mathrm{Ft}}
$$

$$
\mathrm{H}^{*} \quad \text { AssocPA } \mathrm{H}^{*}
$$

The proposal, then, is that the strong form of a function word that is in focus is called for by an independently required constraint on the relation between tonal structure and prosodic structure. The surface form of a nonfocussed function word, by contrast, arguably results from the interplay of constraints on prosodic domination and constraints on the alignment of morphosyntactic and prosodic structure.

2.2 Fnc in isolation A function word uttered in isolation appears in strong form, cf. (9). Its foot-head status falls out immediately from the basic prosodic structure principle of Headedness. An isolation pronunciation is an utterance; an utterance is analyzed at the highest level of prosodic structure, the prosodic category Utterance (Utt). Assuming the Prosodic Hierarchy in (3), by Headedness, Utt must dominate an Intonational Phrase (IP), IP must dominate a Phonological Phrase (PPh), a PPh must dominate a PWd, and a PWd a Ft, hence the strong form of the isolation pronunciation of a monosyllabic Fnc: 
Note that this representation violates PWdCon, the pair of constraints which require that for every $\mathrm{L} / \mathrm{R}$ edge of $\mathrm{PWd}$ in $\mathrm{P}$-structure there is a $\mathrm{L} / \mathrm{R}$ edge of some Lex in S-structure. Given an optimality-theoretic approach, the violation of PWdCon is ascribed to the higher ranking of Headedness in the constraint hierarchy. Indeed, since Headedness is a defining property of prosodic structure, it may be considered to be inviolable, more highly ranked than any other violable constraint.

$$
\text { Headedness }>>\ldots \text {. > PWdCon } \ldots
$$

Quite generally, the inviolability of Headedness makes the prediction that any word pronounced in isolation would have the prosodic properties of entities at all the levels of the Prosodic Hierarchy. This prediction appears to be borne out in English and elsewhere.

2.3 Nonfinal Fnc It is a fact that, in the absence of pitch accent, the prosodic structure of a Fnc word correlates with the position in which that Fnc is embedded in the sentence. A Fnc followed by a Lex within the same syntactic phrase standardly appears in weak form:

(16) Diane $\mathbf{c a}^{\circ} \mathbf{n}$ paint $\mathbf{h} \mathbf{e}^{\circ} \mathbf{r}$ portrait $\mathbf{o}^{\circ} \mathbf{f}$ Timothy $\mathbf{a}^{\circ} \mathbf{t}$ home.

$\mathbf{B u}^{\circ} \mathbf{t s h e}^{\circ}$ found tha ${ }^{\circ}$ the ${ }^{\circ}$ weather wa ${ }^{\circ}$ s too hot fo ${ }^{\circ} \mathbf{r}$ painting. 
I will assume that such Fnc-Lex sequences appear in the phrase structure configuration in (17a), one in which the function word heads a functional phrase FncP within which it is followed by a phrase LexP that is itself headed by Lex ${ }^{8}$. The structures in b. and c. are representative examples.
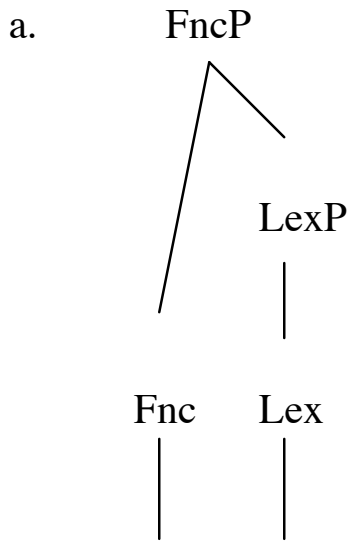

fnc lex b.
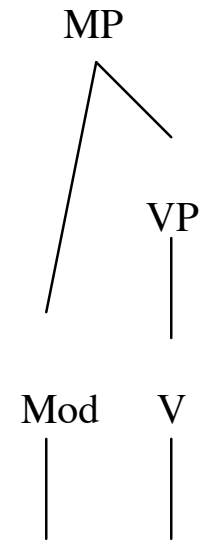

can paint c. DP
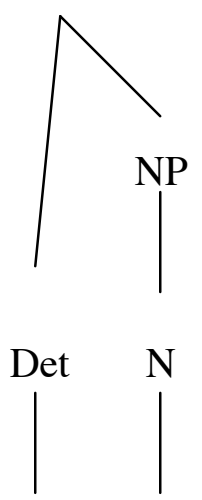

the weather

It is on the basis of such inputs, then, that the grammar of constraints on prosodic structure must derive the weak prosodic clitic form of the function word in the output.

As pointed out in the introduction, there are in principle a number of different prosodic structures in which a function word in structures like (17) may appear. So the first question to be addressed here is an empirical one. Which prosodic structure correctly represents the structure of non-phrase-final weak function words in English like these? The candidates in (18a-d) represent the four different possible organizations of function words into PWd given above in (2). 
They have in common that the function word has the representation of a stressless syllable (one which does not head a foot).

(a)

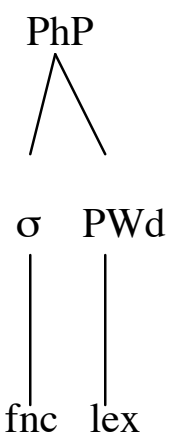

(b)
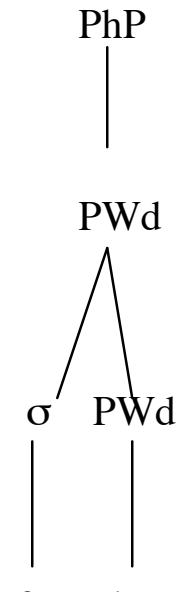

fnc lex (c)

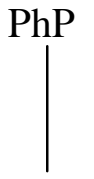

PWd
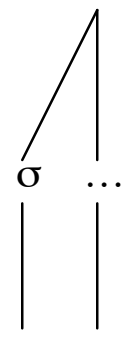

fnc lex (d) $\mathrm{PhP}$

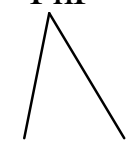

PWd PWd
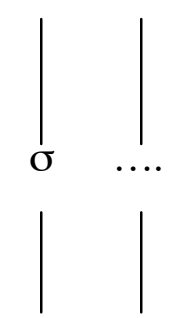

fnc lex

In (18a) fnc is a free clitic; in (18b) it is an affixal clitic; in (18c) it is an internal clitic; and in (18d) it is a prosodic word.

(18d) violates the inviolable constraint Headedness, which calls for every PWd to dominate at least one Ft, and therefore is excluded. Note that if $f n c$ in (18d) were also to be a foot, in accordance with Headedness, then it would have the status of a stressed syllable, contrary to fact. So (18d) is not a possible prosodization for a weak form Fnc.

Neither is (18c) a possible representation of non-phrase-final stressless monosyllabic function words. In this representation, that of an internal clitic, fnc and lex are dominated by the same, single, PWd. This representation implies that 
a Fnc-Lex combination should display phonological behavior identical to that of PWd constituted of a single Lex alone, and this is arguably not correct. It is a well known fact about patterns of English stress that at most one stressless syllable may occur at the left edge of a Lex:

$$
\begin{array}{ll}
\text { ma }{ }^{\circ} \text { sságe } & \text { Màssa }^{\circ} \text { chúse }{ }^{\circ} \text { tts, }{ }^{*} \mathrm{Ma}^{\circ} \text { ssa }^{\circ} \text { chúse }{ }^{\circ} \text { tts } \\
\text { te }{ }^{\circ} \text { nácity } & \text { Tènne }^{\circ} \text { ssée, }{ }^{*} \mathrm{Te}^{\circ} \mathrm{nne}^{\circ} \text { ssée } \\
\text { te lépathy } & \text { tèle }{ }^{\circ} \text { páthic, }{ }^{*} \text { te }^{\circ} \mathrm{le}^{\circ} \text { páthic }
\end{array}
$$

McCarthy and Prince 1993b suggest that this fact argues for the existence of an alignment constraint of the Align (PCat; PCat) variety, whereby the left edge of any PWd is required to coincide with the left edge of a Foot:

(20) Align (PWd, L; Ft, L)

If we assume on the basis of the evidence in (19) that this constraint goes unviolated as long as the initial syllable(s) of a PWd can indeed be organized into a well-formed foot, then it follows that non-phrase-final function words do not have the structure of $(18 \mathrm{c})$. This is because sequences of stressless syllables made up wholly or in part by non-phrase-final function words are systematically possible, in violation of (20).
(i) $\quad a^{\circ}$ méssage
$\mathrm{a}^{\circ}$ ma $^{\circ}$ sságe
fo ${ }^{\circ} \mathrm{r}$ cónferences $\quad$ fo ${ }^{\circ} \mathrm{r} \mathrm{co}^{\circ}$ nvérsions
he ${ }^{\circ}$ áptitude
he ${ }^{\circ} \mathrm{a}^{\circ} \mathrm{b}$ ílities 


$$
\text { ca }{ }^{\circ} \text { pérch } \quad \mathrm{ca}^{\circ} \mathrm{n} \text { pe }{ }^{\circ} \text { rtúrb }
$$

$$
\begin{aligned}
& \text { fo }{ }^{\circ} \mathrm{a}^{\circ} \text { méssage fo }{ }^{\circ} \mathrm{r} \mathrm{a}^{\circ} \mathrm{ma}^{\circ} \text { sságe } \\
& \mathrm{o}^{\circ} \mathrm{r} \text { fo }{ }^{\circ} \mathrm{r} \text { cónferences } \quad \mathrm{o}^{\circ} \mathrm{r} \quad \text { fo }^{\circ} \mathrm{r} \quad \mathrm{co}^{\circ} \text { nvérsions, } \quad \mathrm{o}^{\circ} \mathrm{r} \quad \text { fo }{ }^{\circ} \mathrm{r} \quad \mathrm{a}^{\circ}
\end{aligned}
$$

co ${ }^{\circ}$ vérsion

$$
\begin{array}{ll}
\mathrm{a}^{\circ} \mathrm{t} \text { he }{ }^{\circ} \mathrm{r} \text { áptitude } & \mathrm{a}^{\circ} \mathrm{t} \text { he }{ }^{\circ} \mathrm{r} \mathrm{a}^{\circ} \text { bílities } \\
\text { yo }^{\circ} \mathrm{u} \mathrm{ca}^{\circ} \text { n pérch } & \text { yo }^{\circ} \mathrm{ca}^{\circ} \text { n pe }{ }^{\circ} \text { rtúrb }
\end{array}
$$

Therefore, (18c) is not a possible representation for a non-phrase-final Fnc. Anticipating the discussion below, note that the presence of aspiration in a Lexinitial stressless syllable following a Fnc, e.g. a $c^{h}$ onversion, in $T^{h}$ oronto, provides additional evidence against an internal clitic analysis of the function words. This strucure would lack the aspiration-triggering PWd edge at the left edge of the Lex.)

In contrast, either of the representations (18a) or (18b) would allow for sequences of stressless syllables such as those in (21) without incurring a violation of constraint (20). In (18a), the fnc is not PWd-initial, and hence would not be subject to the constraint Align (PWd, L; Ft, L) in the first place. In (18b), the $f n c$ is PWd-initial, but so is any syllable that follows it (because of the recursive PWd structure there). In this case no Ft could dominate the two, since the resulting structure would not constitute a well-formed bracketing. Which means that positing (18b) would not lead to the prediction that the fnc should be 
stressed if followed by a stressless syllable. What further empirical considerations, then, might decide between these two remaining structures?

Initial position in PWd is often associated with effects involving the phonetic realization of segments. In English, a word-initial voiceless stop is aspirated, even when the syllable to which it belongs is stressless.

$$
\text { grow } \mathbf{t}^{\mathbf{h}} \text { omatoes, grow } \mathbf{p}^{\mathbf{h}} \text { etunias, grow } \mathbf{c}^{\mathbf{h}} \text { alendula }
$$

Cooper 1991, 1994 shows that there is a distinct word-initial aspiration effect (one which cannot be reduced to a simple syllable-initial effect). Prosodic structure theory takes such 'word-initial' effects to be PWd-initial effects. It is significant, therefore, that aspiration does not appear to be attested in initial position in weak non-phrase-final function words, as shown among other things, by the appearance of the flapped version of $t$ (impossible in word-initial position):

(23) They grow to the sky. So can delphiniums. Take Grey to London.

It can therefore be concluded that function words in this position do not initiate PWds, as (18b) would have it, and instead that they are immediately dominated by $\mathrm{PhP}$, as in (18a), and illustrated here ${ }^{9}$ :

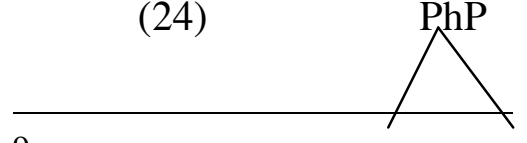

9 A small subset of English monosyllabic function words, the ones written as orthographic 'contractions', Ch. 7). The e.g. Mary's coming, Nina's left, I'll leave too, I'd like to stay, behave as if they are enclitic to the preceding word (Kaisse 1985, Klavans 1985, Inkeles 1989), rather than proclitic to the Lex in the following PPh, as the account given here would predict. It is an interesting fact that these contracted forms are only possible if they are 


$\begin{array}{ll}\sigma & \text { PWd } \\ \text { to } & \text { London } \\ \text { a } & \text { massage } \\ \text { can } & \text { paint } \\ \text { her } & \text { portrait }\end{array}$

The next question to ask, the analytical one, is why it is (18a) rather than one of the set (18b-d), which is the optimal (grammatical) representation of nonphrase-final function words in English. It is here that optimality theory comes crucially into play. Note that all of the representations in (18a-d) violate some constraint. (25) lists the representations and the constraints they violate. We saw above that the optimal output representation is $(18 \mathrm{a}) /(25 \mathrm{i})$, which violates only $\mathrm{Exh}_{\mathrm{PPh}}$. Optimality theory holds that constraints on phonological representation are violable. That is, the grammatical, optimal, output prosodic representation that the constraint hierarchy of a grammar defines based on a particular input morphosyntactic representation may violate some constraint. Such surface violations in an optimal output form are claimed to occur under two circumstances: (i) when the alternative, nonoptimal, output representations that could be constructed (based on the same input) violate a constraint that is higher ranked than the constraint violated in the optimal representation, or (ii) when the alternative candidates contain more violations of the same constraint, or of some other same-ranked constraint(s). 
[since $\mathrm{PPh}$ immediately dominates

$\sigma]$

(ii) $\quad{ }_{\mathrm{PPh}}\left(\mathrm{PWd}_{\mathrm{PW}}\left(\text { fnc }{ }_{\mathrm{PWd}}(\text { lex })_{\mathrm{PWd}}\right)_{\mathrm{PWd}}\right)_{\mathrm{PPh}}$

NonRec $_{P W d}$, PWdCon

$\left[\right.$ NonRec $_{\mathrm{PWd}}$ since PWd dominates

PWd; PWdCon since L edge of PWd

not aligned with L edge of a Lex]

[WdCon since L edge of Lex not aligned with L edge of some PWd; PWdCon since L edge of PWd not aligned with L edge of some Lex]

(iv) $\quad{ }_{\mathrm{PPh}}\left(\mathrm{PWW}_{\mathrm{P}}(\text { fnc })_{\mathrm{PWd}} \mathrm{PWd}_{\mathrm{d}}(\text { lex })_{\mathrm{PWd}}\right)_{\mathrm{PPh}}$

PWdCon (twice), Headedness

[PWdCon since $\mathrm{L}$ and $\mathrm{R}$ edges of the lefthand PWd not aligned with $\mathrm{L} / \mathrm{R}$ edges of some Lex; Headedness since one PWd lacks a Foot head]

No clear indication of the relative ranking of the constraints at issue emerges from the observations in (25). The fact that the optimal candidate (18a)/(25i) incurs 
just a single constraint violation while the other nonoptimal candidates incur violations of at least two other constraints is consistent with a variety of possible constraint rankings. Only examination of further data will enable us to decide on the correct ranking. Given the data at hand, it could simply be that $\operatorname{Exh}_{\mathrm{PPh}}$ is dominated by all the other constraints at issue: Headedness, NonRec ${ }_{\mathrm{PWd}}$, WdCon, $\mathrm{PWdCon}_{\mathrm{L}}$ and $\mathrm{PWdCon}_{\mathrm{R}}$. This would explain why the free clitic candidate violating $\operatorname{Exh}_{\mathrm{PPh}}$ is the optimal one. On the other hand, it could also be that, except for the undominated Headedness, all the constraints have the same rank. In this case, the mere fact that the free clitic candidate has the fewest violations would decide in its favor. It could also be that $\mathrm{Exh}_{\mathrm{PPh}}$, is ranked lower than, say, NonRec $_{\mathrm{PPh}}$ and $\mathrm{WdCon}$ (as well as Headedness), but same ranked with respect to PWdCon. In this latter case, the violations of Headedness, WdCon and NonRec $_{\mathrm{PWd}}$ seen in each of the other respective candidates would be fatal to them. The evidence we will consider in the sections to follow gives support for ranking both $\operatorname{Exh}_{\mathrm{PPh}}$ and PWdCon below NonRec $\mathrm{PWd}_{\mathrm{P}}$ and $\mathrm{WdCon}$, and is thus consistent with the latter ranking ${ }^{10}$.

\subsection{Final Fnc Consider next the case of monosyllabic Fnc appearing in} phrase-final position. The italicized function words in (27) appear in strong form, and can not appear in the weak form they may adopt when not phrase-final.

10 There is a class of candidate output structures for a [[fnc] [lex] input that were not considered above: ones with a Foot dominating the monosyllabic $f n c$, where the $f n c$ would therefore be interpreted as stressed. The absence of Foot dominating the monosyllabic fnc in the optimal candidate is arguably a consequence of the general principle calling for a minimization of structure (cf. Selkirk and Shen 1990), codified in optimality theory as the constraint *Struc (Prince and Smolensky 1993). *Struc says, in effect, all else being equal, 'less is best'. Thus, if the constraints and their ranking do not call for the presence of Foot dominating the monosyllabic fnc, then no Foot will appear. 
If you think you cán, go ahead and do it.

I don't know whether Ray ís. $\quad$ [îz], *[z]

Wherever Ray is, he's having a good time.

What did you look át yesterday? $\quad$ [æt $]$ * * $[\backslash \mathrm{t}]$

Who did you do it fór that time? [før], *[fr $\leq]$

Given that they are stressed we know that these monosyllables have at least the status of a foot, i.e. $\left((\mathrm{fnc})_{\mathrm{Ft}_{\mathrm{Ft}}}\right.$. Further evidence suggests that phrase-final Fnc elements are final in a PWd. The evidence comes from the behavior of intrusive $r$ in the Eastern Massachusetts dialect described by McCarthy $(1991,1993)$.

Intrusive $r$ is inserted after a word-final low vowel when the following word begins with a vowel. Significantly, McCarthy shows, intrusive $r$ appears in just two contexts: at the right edge of Lex, (28i-a), and at the right edge of a phrase-final Fnc, (28i-b). It never appears at the right edge of non-phrase-final Fnc, $(28 \mathrm{ii})^{11}$.

\section{(i) Presence of Intrusive $\mathbf{r}$}

a. After Lex

Actually, *Struc could also provide an explanation for the lack of a PWd dominating the monosyllabic fnc in the optimal output of a [[fnc][lex]] input, thereby depriving PWdCon of some of its motivation. In what follows I will assume a role for PWdCon, but keep in mind the possibility that it might be supplanted by *Struc.

11 This table of facts is due to McCarthy 1991, 1993 and to a 1994 class lecture handout. 
The spa-r is broken.

He put the tuna-r on the table.

The boat'll yaw-r a little.

schwa-r epenthesis

Wanda-r is coming.

a Pollyana-r-ish attitude saw-r-ing

rumba-r-ing

guffaw-r-ing

subpoena-r-ing

baah-r-ing (of sheep)

b. After phrase-final Fnc (compare to examples in (ii))

I said I was gonna-r and I did.

Did you-r, or didn't you.

We oughta-r if we're asked.

If you hafta-r, I'll help.

\section{(ii) Lack of Intrusive $\mathbf{r}$ after non-phrase-final Fnc}

a. Modal + reduced have

should have (shoulda), could have (coulda), might have (mighta)

He shoulda eaten already. $\quad[\beta * d \backslash(* r) i j \div \backslash n \leq]$

b. Fnc-like verbs + reduced to

going to (gonna), ought to (oughta), have/has to (hafta, hasta), got

to (gotta), used to (useta), supposed to (supposta) 
I'm gonna ask Adrian. [g $\sqrt{ } \mathrm{n} \backslash\left({ }^{*} \mathrm{r}\right)$ æsk]

c. Auxiliary + reduced you

did you, should you, would you, could you

Did you answer him? [dîd $\Omega \backslash\left(*^{*}\right)$ æns \r ^m]

d. Reduced to, do, of

To add to his troubles $\left[\mathrm{t} \backslash\left(*^{*}\right)\right.$ æd $\left.\mathrm{t} \backslash\left({ }^{*} \mathrm{r}\right)^{\wedge} \mathrm{z} \operatorname{tr} \backslash \mathrm{bl} \leq \mathrm{z}\right]$

Why do Albert and you [waj $d \backslash(* r) æ l b \backslash t \backslash n$ juw]
A lotta apples
$[\backslash \operatorname{løt} \backslash(* r) æ p l \leq z$

The McCarthy analysis is that PWd-final position defines the locus of intrusive $r$ insertion. This analysis assumes, and at the same time gives crucial support for, the generalization that a phrase-final function word is PWd-final. An additional set of examples shows that a phrase-final Fnc is preceded by a PWd as well:

(29) It's more scary than a subpoena-r is.

What did they convict Wanda-r of?

That's nothing to guffaw-r at! 
The appearance of intrusive $r$ at the end of the lexical word preceding the phrasefinal fnc indicates that the lex is PWd final.

This evidence from intrusive $r$ is consistent with two possible surface prosodic structures for phrase-final $f n c$ : $(l e x)_{\mathrm{PWd}}(f n c)_{\mathrm{PWd}}$, in which the $f n c$ is a PWd on its own, and $\left((l e x)_{\mathrm{PWd}} f n c\right)_{\mathrm{PWd}}$, in which the $f n c$ is located in a nested PWd structure. In both cases the phrase-final fnc is PWd-final, and so is the preceding lex. But only the analysis of the fnc as a PWd itself will explain why it is always stressed. By assuming that the fnc is a PWd (rather than just as the end of one), its stressedness simply falls out from Headedness, which entails its Foot-head status. So we conclude in the PWd status of phrase-final Fnc.

The question then is why phrase-final function words have the status of PWd, in violation of PWdCon. Why aren't they simply one of the variety of prosodic clitics that are in principle available? In particular, why aren't they free clitics, just like the non-phrase-final $f n c$ are? This is what the grammar as currently constituted would predict. Explaining the asymmetry in the prosodic status of phrase-final and non-phrase-final Fnc will therefore require appeal to some constraint(s) that have not yet had a crucial role to play. I believe the relevant constraints concern prosodic structure at the level of the phonological phrase.

It has often been observed that phonological phrase breaks typically occur at the edges of morphosyntactic phrases. Investigation of the sentence phonology of a variety of languages has led to the conclusion that there are alignment 
constraints requiring that the Right, or Left, edge of a maximal phrasal projection coincide with the edge of a phonological phrase ( $\mathrm{PPh}$ ) (See references in footnote 5). More specifically, the phrasal alignment appears to be defined with respect to Lex $^{\text {max }}$, the maximal phrase projected from a Lex (Selkirk and Shen 1990). These constraints are expressed in the generalized alignment format as (30):

a. $\quad$ Align (Lex $\left.{ }^{\max }, \mathrm{R} ; \mathrm{PPh}, \mathrm{R}\right)$

b. $\quad$ Align $\left(\operatorname{Lex}^{\max }, \mathrm{L} ; \mathrm{PPh}, \mathrm{L}\right)$

They state that the right (resp. left) edge of any Lex ${ }^{\max }$ in morphosyntactic structure coincides with the right (resp. left) edge of some phonological phrase in prosodic structure. The two constraints, available universally, must be independently rankable, for it has been shown that languages may show either predominantly right edge or left edge effects. As for English, the PWd status of phrase-final Fnc suggests very strongly that the constraint (30a) calling for the alignment of a $\mathrm{PPh}$ edge with the right edge of a maximal projection is higher ranked than any of the other constraints under consideration ${ }^{12}$.

If we assume that Align $\left(\mathrm{Lex}^{\max } ; \mathrm{PPh}\right)$ is for all intents and purposes an undominated constraint in English, this means any element that is final in a morphosyntactic phrase will also be final in a phonological phrase. The sentence

12 Independent evidence for or against this right-edge alignment of phonological and syntactic phrases in English will most likely come from phenomena involving intonation or durational patterns, which are argued to be characterized in terms of phrase-sized units of prosodic structure (cf. Beckman and Pierrehumbert 1986, Beckman and Edwards 1990, Shattuck-Hufnagel, Ostendorf and Ross 1993). 
in (31a), with its morphosyntactic phrase-final Fnc át, will be parsed into phonological phrases as in (31b) in all of the candidate output representations, putting át in PPh-final position.

(31) a. [What did you $\mathrm{vP}_{\mathrm{VP}}\left[\mathrm{look}_{\mathrm{PP}}\left[\mathrm{at} \_\right]_{\mathrm{PP}}\right]_{\mathrm{VP}}$ last time]

b. ${ }_{\mathrm{PPh}}(\text { What did you look át })_{\mathrm{PPh} P h}(\text { last time })_{\mathrm{PPh}}$

Observe that the candidates for the output representation of look at which satisfy Align (Lex $\left.{ }^{\max } ; \mathrm{PPh}\right)$, as well as Headedness, include the following:

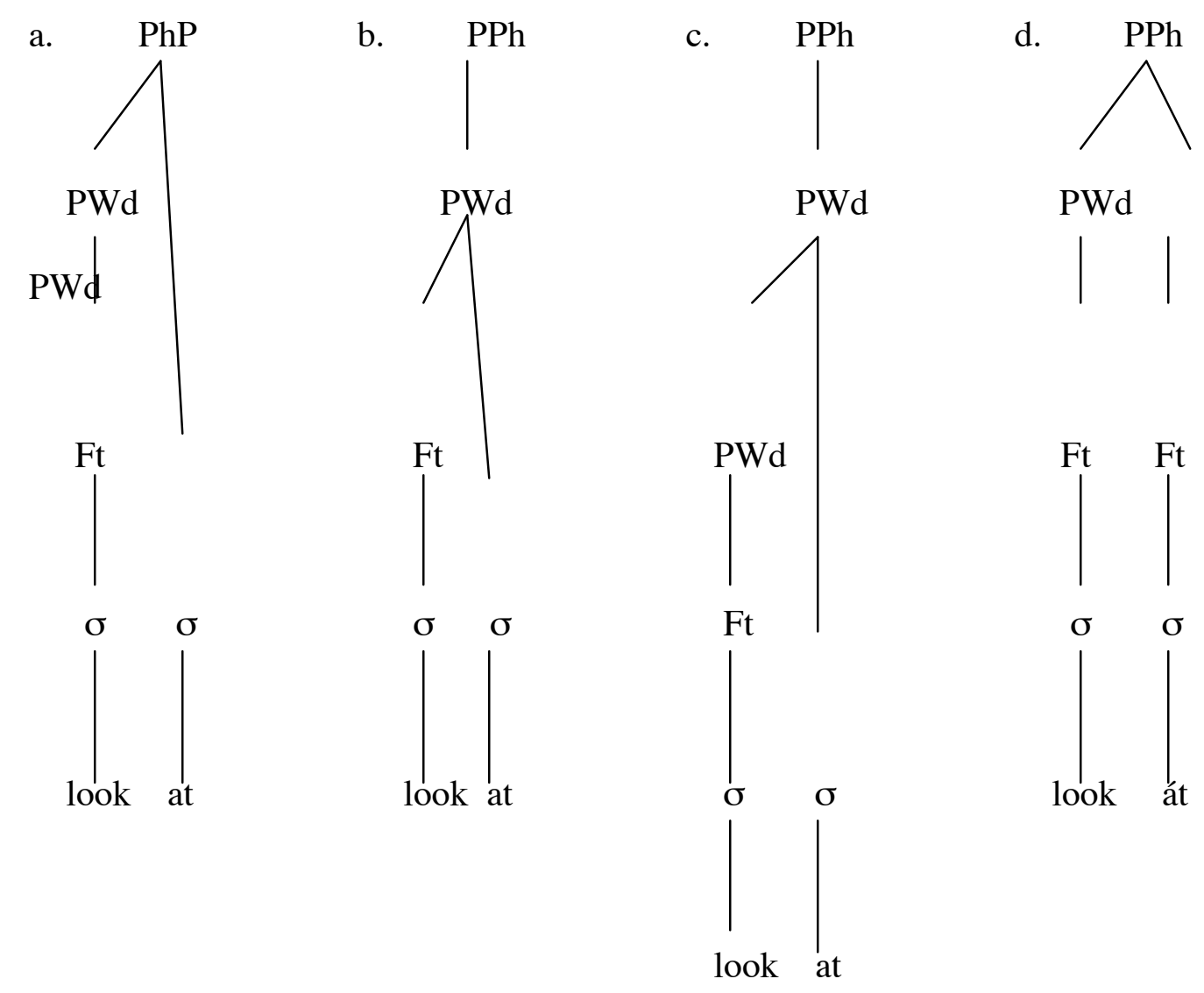


An explanation for the non-optimality of the free clitic case in (32a) now suggests itself, namely that there is a constraint that calls for the right edge of a PPh to be aligned with the right edge of a PWd, and that it is violated in candidate (a). This is just the sort of constraint that alignment theory claims will be typically seen to play a role in grammars, a constraint of the Align (PCat; PCat) family:

\section{(33) Align (PPh, R; PWd, R)}

If unviolated, this constraint ensures that, given the presence of a $\mathrm{PPh}$ edge after át (itself called for by Align (Lex $\left.{ }^{\max }, \mathrm{R} ; \mathrm{PPh}, \mathrm{R}\right)$, there must be also a PWd edge after át. It excludes the free clitic candidate (a), and provides the basis for an explanation for the asymmetry between phrase-final and non-phrase-final prosodizations in English. The ordering of Align $\left(\mathrm{Lex}^{\max } ; \mathrm{PPh}\right)$ and Align $(\mathrm{PPh} ; \mathrm{PWd})$ the constraints violated in $\mathrm{b}-\mathrm{c}$ is all that it takes to render the free clitic candidate non-optimal:

$$
\text { Align (Lex }{ }^{\text {max }} \text {;PPh), Align }(\mathrm{PPh} ; \mathrm{PWd})>>\text { WdCon, NonRec }{ }_{\mathrm{PWd}}, \mathrm{PWdCon}
$$

Assuming these phrasal alignment constraints and the constraint hierarchy in (34) doesn't, however, provide an explanation for why the optimal candidate is (d), rather than the affixal or internal clitic candidates (b-c), since in them at is also PWd-final in PPh. But the explanation is readily available. In order that (d) be chosen instead of $(b, c)$ we need only assume that $\mathrm{WdCon}$ and $\mathrm{NonRec}_{\mathrm{PWd}}$ are ranked higher than PWdCon: 
(Recall that no ranking amongst these constraints was earlier established.) The optimality theoretic ranking of WdCon above PWdCon means that the candidate violating WdCon, (b), is "less well-formed" than the candidate violating PWdCon, (d). ((b) violates WdCon since there is no PWd edge at the right edge of look.) And the ranking of NonRec $\mathrm{PWd}_{\mathrm{d}}$ above PWdCon rules (c) "less well-formed" than (d). (The nested PWd structure of (c) violates NonRec $_{\mathrm{PWd}}$.) So despite the violations of PWdCon seen in it, (d) is the "best-formed" candidate relative to the others, i.e. the optimal one.

Putting together the assumptions about constraint rankings that have been posited thus far (in (34), (35) and the final paragraph of section 2.3), we see they are consistent with each other, and give the amalgamated ranking in (36):

$$
\text { Align Lex }{ }^{\max } \text {, Aliqn PPh }>>\text { WdCon, NonRec }{ }_{\mathrm{PWd}} \gg>\text { PWdCon, Exh }{ }_{\mathrm{PPh}}
$$

(This ranking mentions only constraints that are assumed to be violable. A full ranking statement would include Headedness and Layeredness, universally undominated constraints, at the left extreme.)

2.5 Morphosyntactic enclitic Fnc? Object pronouns present a special case: they may appear either in strong form or in weak form (cf. Selkirk 1972, 1984). There are pronunciations of verb plus object pronoun, for example, in which the 
phonetic realization of the pronoun and its rhythmic adherence to the verb is identical to that of a word-final stressless syllable.

$\begin{array}{llll}\text { need him, them } & \approx & \text { Needham } & {[\text { nidm } \leq]} \\ \text { will it } & \approx \text { billet } & {[\text { bîlit }]} \\ \text { stroke her } & \approx & \text { stroker } & {[\text { strokr } \leq]} \\ \text { feed us } & \approx \text { fetus } & {[\text { fidîs }]} \\ \text { gimme (give me) } & \approx \text { Jimmy } & {[\text { dzimi }]} \\ \text { see you } & \approx \text { Mia } & {[\text { mijj] }}\end{array}$

Such a pronunication is not necessary, however. Pronouns in the locutions in (37a) may also be pronounced in strong form, e.g. hím [hîm], thém [†'m], hér [hr $\leq]$, ít [ît], yóu [juw], mé [mij], ús [ $\left.\bigvee_{\mathrm{s}}\right]$. The appearance of these phrase-final pronouns in strong form is what is expected, given the constraint hierarchy posited thus far, if we assume that in the input morphosyntactic representation the pronoun has the status of a phrasal object of the verb, as in (38a).

a.
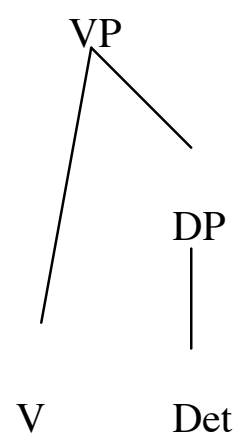

b. $\left((\text { need })_{\mathrm{PWd}}(\text { him })_{\mathrm{PWd}}\right)_{\mathrm{PPh}}$ 
c. $\left((\text { need })_{\mathrm{PWd}} \text { 'm }\right)_{\mathrm{PWd}}$

Given this input, the constraint hierarchy predicts the prosodic structure in (38b), where the pronoun is a PWd on its own, hence a Foot, hence stressed and in unreduced strong form, just like stranded át in look át. However, the weak form option that the pronouns may display in (37) indicates that in this case they do not, on their own, have the status of PWd. Rather, the reduced object pronouns arguably have the status of affixal clitics, situated in a nested PWd structure as in (38c).

Intrusive $r$ facts show that a reduced object pronoun that is phrase-final is indeed final in a $\mathrm{PWd}^{13}$ :

(39) I saw ya-r and asked about it

If I see ya-r, I'll ignore ya.

I'll see ya-r if I get done on time.

Moreover, a low-vowel-final verb before a vowel-initial weak object pronoun shows intrusive $r$, indicating that a PWd boundary follows it and precedes the pronoun:

(40) saw-r us, withdraw-r it, subpoena-r him

The evidence thus points to a nested PWd structure for reduced object pronouns ${ }^{14}$. The task, then, is to explain why it is that object pronouns have the option of 
appearing in either one of these two different prosodic structure configurations. What is it that is special about object pronouns that allows them these options?

Suppose we entertain the hypothesis that what's special about object pronouns in English is captured in the morphosyntactic component of the grammar. In quite a variety of other languages, including the Romance languages and Arabic, object pronouns are taken to form a constituent with the verb, that is, they are morphosyntactic clitics. Suppose now that this morphosyntactic clitic analysis were optionally available for object pronouns in English:

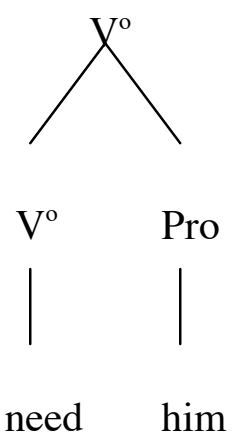

It's easy to see why such an input structure, with its nesting of constituents of category type Lex, would give rise to a nested PWd structure in the output of the phonology. Such an output would simply respect the alignment constraint WdCon, which calls for a right (resp. left) PWd edge at every right (resp. left) Lex edge in the morphosyntactic input representation. A constraint ranking of WdCon higher than $\operatorname{NonRec}_{\mathrm{Pwd}_{\mathrm{d}}}$ would therefore explain why the latter constraint is violated in the prosodic affixal clitic output. Note that in the constraint ranking 
(36) that we arrived at on the basis of earlier evidence, WdCon and NonRec $_{\mathrm{PWd}_{\mathrm{d}}}$ occupy the same niche in the constraint hierarchy. This is because their relative ordering was immaterial in accounting for the earlier data. If the constraint

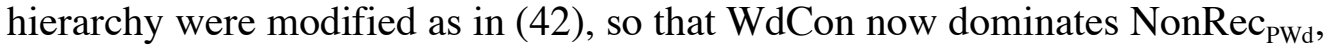

$$
\text { Align Lex }{ }^{\max } \text {, Align PPh }>>\text { WdCon }>>\text { NonRec }_{\mathrm{PWd}}>>\text { PWdCon, } \mathrm{Exh}_{\mathrm{PPh}}
$$

we would not only retain the account of the earlier data, we would be able to derive the nested PWd structure from the nested verb structure in (41) as well.

The fact that the minimally modified grammar of constraints in (42) can derive the variant forms of object pronouns simply by assuming that the morphosyntax generates both structure (38) and (41) for object pronouns makes this approach to the object pronoun options in English quite appealing. Of course, confirmation of these assumptions about the morphosyntactic input based on an independent morphosyntactic analysis of English object pronoun constructions would be required before we could commit ourselves to this solution ${ }^{15}$.

An alternative approach to accounting for the specialness of object pronouns would assume a single morphosyntactic object pronoun structure in the input to the phonology, presumably the phrasal object structure, and ascribe the

14 The fact that in double pronoun object constructions one finds no intrusive $r$ after reduced you (give ya it NOT * give ya-r it $)$ suggests that the two pronoun clitics are sisters in prosodic structure: $\left((\text { give })_{\mathrm{PWd}} \mathrm{ya} \text { it }\right)_{\mathrm{PWd}}$. 15 One important fact that a morphosyntactic clitic analysis of object pronouns would have to confront is the apparent restriction to intrusive $r$ after reduced you to VP-final positions:

I'll get ya $(* r)$ another one.

I'll call ya(*r) up. 
options in surface prosodization to the constraint system of the phonological component, suitably revised. A constraint would be required that ruled out strong form pronouns, say $*(\text { Pro })_{\mathrm{PWd}}$, and its ranking would have to be such that both options in prosodization would be ruled optimal ${ }^{16}$. It turns out that assigning $*(\mathrm{Pro})_{\mathrm{PWd}}$ the same ranking as $\mathrm{NonRec}_{\mathrm{PWd}}$ in the constraint hierarchy given in the revised ranking (42) has precisely the consequence that phrase-final object pronouns would have the prosodic options they do: one option violates NonRec $_{\mathrm{PWd}}$, the other violates $*(\mathrm{Pro})_{\mathrm{PWd}}$, but they are both equally well-formed with respect to the other constraints ${ }^{17}$.

In any case, what is clear about phrase-final object pronouns is that they may appear with two different surface prosodizations: as a prosodic clitic of the affixal variety or, like other phrase-final function words, as a prosodic word. And it is clear that, in some way, the grammar must single out pronouns from other functional elements. Deciding between the two alternative approaches sketched here will have to await further research.

2.6 Summary To sum up, we have seen evidence for three different prosodic structures for function words in English, (43b). These different prosodizations may be ascribed to differences in the morphosyntactic inputs, (43a):

We saw ya(*r) on TV.

16 This particular line on the problem of pronoun options was suggested to me by John McCarthy. 
a.

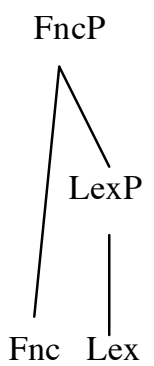

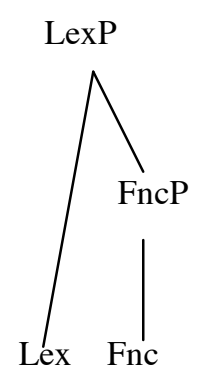

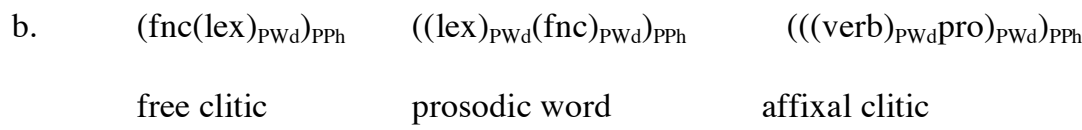

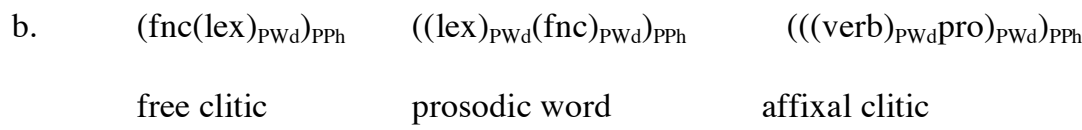

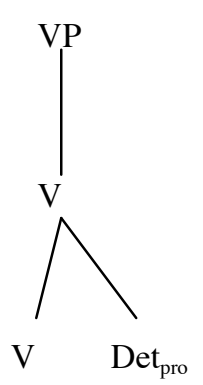

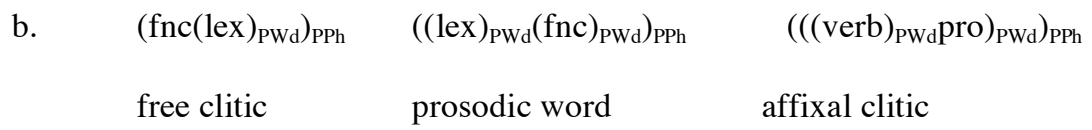

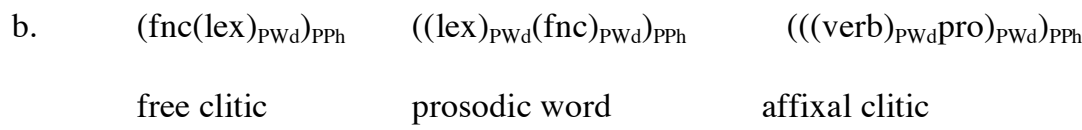

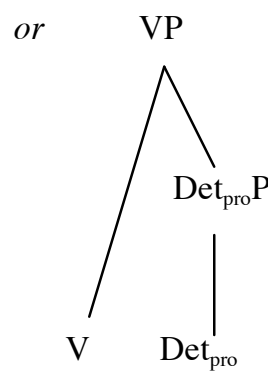

Given the different inputs, the grammar of constraints, organized in the hierarchy of domination argued for above, derives these outputs. The optimality theoretic hypothesis is that the constraints are universal, but the hierarchical ordering of constraints is not. With modifications in the constraint hierarchy, different pairings of morphosyntactic input and prosodic output would be derivable.

\section{Accent and Prosodic Word in Serbo-Croatian}

Because languages may differ in constraint ordering, it is predicted that in different languages (or dialects) an identical morphosyntactic input structure may give rise to different optimal prosodic structure outputs. We see just such a case in the three Neoṣtokavian (NS) dialects of Serbo-Croatian analyzed by Zec 1993, who argues that dialect differences in the realization of tonal word accents in the 
same morphosyntactic environment reflect systematic differences in the organization of function words into prosodic words.

The underlying representation of root or affixal morphemes in SerboCroatian may or may not contain a high $(\mathrm{H})$ tone accent. When a lexical category word does not contain any underlyingly accented morphemes, a default accent must be assigned. In all the NS dialects, an unaccented lexical word like graad will receive a default accent on its initial mora when preceded by another Lex word in the sentence, e.g. (44), where vidiim is underlying accented.

$\begin{array}{lcc}\mathrm{H} & \mathrm{H} & \mathrm{H} \\ \mathrm{I} & \mathrm{I} & \mathrm{I} \\ \text { vidiim 'I see' + graad 'city' --> vidiim graad 'I see a city' }\end{array}$

When an unaccented Lex is preceded by a function word within the same syntactic phrase, however, there are dialect differences in the treatment of default accent.

NS-3:

$\begin{array}{llll}\mathrm{H} & \mathrm{H} & \mathrm{H} \text { or } & \mathrm{H} \\ \text { u graad } & \text { u graad } & \text { u glaavu } & \text { u glaavu } \\ \text { 'to the city' } & \text { 'to the city' } & \text { 'into (the) head' }\end{array}$

In the NS-1 dialect (E. Herzegovina), the default accent is realized on the first mora of the function word; the lexical word bears no default accent. In the NS-2 
(Belgrade, the standard), the default accent falls on the first mora of the lexical word (where it fails to spread to the preceding function word); the function word bears no accent. And in NS-3 (Srem, Maça) there are two options: the default accent may simply fall on the first mora of the function word, or it may fall on the first mora of the lexical word, in which case it also spreads onto the last mora of the preceding function word ${ }^{18}$. The examples in (45) involve a preposition followed by a noun. Other Fnc Lex combinations are reported to behave in the same way.

Following Zec 1993, I assume (i) that in all dialects there is a constraint, call it Initial Accent, which is responsible for the presence of a default accent on the first mora of a word and (ii) that the differences in assignment of default accent in Fnc-Lex sequences reflect differences in PWd structure. More specifically, if we assume the PWd structures in (46), then the position of the default accent will fall out:

NS-1:

$\mathrm{H}$

।

( u graad $)_{\mathrm{PWd}}$

internal clitic
NS-2:

$\mathrm{H}$

।

$\mathrm{u}(\operatorname{graad})_{\mathrm{PWd}}$

free clitic
NS-3:

\begin{tabular}{lcc}
$\mathrm{H}$ & or & $\mathrm{H}$ \\
$\mathrm{l}$ & $\mathrm{I}$ \\
(u $\left.(\text { glaavu })_{\mathrm{PWd}}\right)_{\mathrm{PWd}}$ & $\left(\mathrm{u}(\text { glaavu })_{\mathrm{PWd}}\right)_{\mathrm{PWd}}$ \\
\multicolumn{2}{c}{ affixal clitic }
\end{tabular}
spreading onto the preceding function word is indeed an instance of this general phenomenon would be provided by polysyllabic function words, if it were the case that only the final mora were spread onto from an accent originating in initial position in the following Lex. Unfortunately the relevant data is not available. 
Assuming an internal clitic analysis for NS-1, only the Fnc is PWd-initial and susceptible of receiving the default accent. If we assume a free clitic analysis for NS-2, the Fnc is not PWd-initial and so cannot receive the accent, which instead must fall in the initial mora of the Lex. As for NS-3, the nested PWd structure of the affixal clitic analysis provides the basis for understanding the options in accent placement that are observed: either on first mora of the PWd-initial Fnc, or on the first mora of the PWd-initial Lex (from which it spreads, to the immediately preceding mora, cf. footnote 16). In NS-3, and quite generally in Serbo-Croatian, two accents are never permitted within the same PWd, therefore the constraint calling for initial default accent can be satisfied only with respect to one of the two nested PWd's. Both options in the realization of initial accent in NS-3 are therefore both equally '(non)wellformed' with respect to the Initial Accent constraint, and hence both are optimal ${ }^{119}$. It would appear, then, that the three Neostokavian dialects exploit the three different types of prosodic clitic structure that the present theory makes available for assigning a surface prosodic structure to a Fnc-Lex sequence in the morphosyntactic input to the phonology.

Just how do the grammars of these dialects differ, then? Only in the ranking of the universal constraints that we have already seen play a role in

19 Since Serbo-Croatian never allows two accents within the same PWd (Lehiste and Ivi_ 1986, Inkelas and Zec 1988, Zec 1994), the fact that both the preposition and the initial mora of the noun bear $\mathrm{H}$ tone in the second option in NS-3 should be analyzed as a double-linking of a single $\mathrm{H}$ accent. Spreading of an underlying accent to immediately preceding mora, creating such a double-linking, is a general phenomenon (cf. note 16), and so this double-linking can be seen an instance of this spreading. The question remains why this spread configuration cannot be seen as satisfying the Initial Accent requirement with respect to both $\mathrm{PWds}$ at the same time. Evidence that it doesn't is the availability of the other option in default accent realization, which incurs one violation of the Initial Accent constraint. It should not be available if the doubly linked option contains no violation of the constraint. The answer probably lies in the characterization of the default accent phenomenon itself and its relation to word stress (see Zec 1994). 
English-- namely the alignment constraints WdCon and PWdCon and the prosodic domination constraints $\operatorname{NonRec}_{\mathrm{PWd}}$ and $\mathrm{Exh}_{\mathrm{PPh}}$ :
a. NS-1: $\operatorname{NonRec}_{\mathrm{PWd}}, \operatorname{Exh}_{\mathrm{PPh}}>>$ WdCon, PWdCon

b. NS-2: WdCon, PWdCon, NonRec $\mathrm{PWd}_{\mathrm{P}} \gg \operatorname{Exh}_{\mathrm{PPh}}$

c. NS-3: WdCon, $\operatorname{Exh}_{\mathrm{PPh}}>>$ NonRec $_{\mathrm{PWd}}$, PWdCon

I leave it to the reader to confirm for themself that these rankings give rise to the different prosodic clitic structures attested, on the basis of a Fnc-Lex input sequence.

\section{Conclusion}

Summing up, we have seen that functional category words are distinguished from lexical category words in that (i) they need not have the status of prosodic word in phonological representation, and (ii) they may appear in a variety of distinct prosodic clitic structures, both cross-lingusitically and in the same language. It was proposed that the first property follows from the invisibility of function words (and functional projections) to constraints governing the interface of prosodic structure and morphosyntactic structure. Of central importance is the notion that the constraint WdCon requires only that the $\mathrm{L} / \mathrm{R}$ 
edges of word-level Lex items align with PWd edges; words of the Fnc variety suffer no such requirement and hence are free to be otherwise organized. The second property, namely the variety in prosodization of function words, can come about in just two different ways, given an optimality theoretic perspective: through differences in the morphosyntactic input structure in which the Fnc is located and/or differences in the ranking of the relevant constraints. The constraints themselves are held to be universal. In English we saw that the same ranking of constraints on prosodic structure will give rise to differences in the prosodic structure of function words when the morphosyntactic input structures differ in relevant ways. In the Serbo Croatian dialects, we saw that function words located in identical morphosyntactic input structures differ in prosodization, and hence that it is differences in the ranking of the relevant constraints that must be given responsibility for this cross-linguistic surface variety in prosodic structure.

Given this understanding of function word prosodization we are in a position to ask in what ways the language learner could conceivably exploit phonological knowledge in learning something about the syntax of the functional/lexical distinction. It does seem that phonology could potentially be of help in learning which words belong to the Fnc category and which to the Lex category. Let us consider the case of English monosyllabic words. Assuming that the child has already learned that there is a prosodically relevant distinction between strong unreduced syllables and weak reduced syllables, they would be in a position to observe in the speech of adults that some words always appear in strong form, while others alternate between weak and strong realizations. Given 
the child's innate knowledge of the universal constraints on prosodic structure, it could conceivably draw the inferences sketched in (48), and thereby make an assignment of monosyllabic words to either the Fnc or the Lex category:

\title{
(48) Inferring Lex/Fnc status from strong/weak status
}

\author{
a. $\quad$ Always strong $(\mathrm{X}) \rightarrow$ Always Foot $(\mathrm{X}) \rightarrow$ Always PWd $(\mathrm{X}) \rightarrow$ Lex $(\mathrm{X})$ \\ b. $\quad \neg$ Always strong $(\mathrm{X}) \rightarrow \neg$ Always Foot $(\mathrm{X}) \rightarrow \neg$ Always PWd $(\mathrm{X}) \rightarrow$ Fnc $(\mathrm{X})$
}

The child learner of English could also, in principle, gain access to information about the surface morphosyntactic phrase structure of the sentence in which a Fnc is embedded, given their knowledge of the universal prosodic constraints at play: strong form status for an unaccented Fnc is ultimately attributable to its morphosyntactic phrase-final position.

All this to say that a certain amount of information about the syntax is retrievable from the phonological contrasts between Lex and Fnc items and the alternations in form that Fnc words exhibit. But retrieving this information assumes the acquisition of sufficient knowledge of the workings of the phonology itself. Whether a child's knowledge of phonology develops early enough to be of use to the acquisition of this aspect of syntax, and in case it does, whether it is indeed exploited, remain questions for future research. 


\section{References}

Abney, S. (1987) The English Noun Phrase in its Sentential Aspect. Ph.D. dissertation, MIT.

Beckman, M. and J. Edwards (1990) Lengthenings and shortenings and the nature of prosodic constituency. In J. Kingston and M. Beckman, eds., Papers in Laboratory Phonology 1: Between the Grammar and Physics of Speech. New York, Cambridge: Cambridge University Press.

Beckman, Mary and Janet Pierrehumbert (1986) Intonational structure in English and Japanese. Phonology 3, 255-309.

Berendson, E. (1986) The Phonology of Cliticization. Ph.D. dissertation, Utrecht.

Bickmore, Lee (1989) Kinyambo Prosody. Ph.D. dissertation, UCLA.

Booij, G. (1983) Principles and parameters in prosodic phonology. Linguistics $21,249-280$.

Borowsky, Toni (1993) On the word-level. In S. Hargus and E. Kaisse, eds., Studies in Lexical Phonology. Phonology and Phonetics, 4. Academic Press, New York.

Chen, Matthew (1987) The syntax of Xiamen tone sandhi. Phonology 4, 109-150.

Chomsky, N. (1986) Barriers. Linguistic Inquiry Monograph 13, MIT Press.

Chomsky, N. and M. Halle (1968) The Sound Pattern of English. New York: Harper and Row. 
Cohn, Abigail (1989) Stress in Indonesian and bracketing paradoxes. Natural Language and Linguistic Theory 7, 167-216.

Cooper, André (1991) An Articulatory Account of Aspiration in English. Ph.D. dissertation, Yale University.

Cooper, Andre (1994) Aspiration in English: How should it be defined and where should it be described?. Manuscript, University of Michigan.

Féry, Caroline (1989) Prosodic and Tonal Structure of Standard German. Ph.D. dissertation, University of Konstanz, published as Arbeitspapier Nr. 9, Fachgruppe Sprachwissenschaft der Universitat Konstanz.

Féry, C. (1993) German Intonational Patterns. Tübingen: Max Niemeyer Verlag. Fukui, N. and M. Speas (1986) Specifiers and Projection. In N. Fukui, T. Rappaport and E. Sagey, eds., MIT Working Papers in Linguistics, MIT. Gimson, A. (1970) An Introduction to the Pronunciation of English. 2nd ed. London: Edward Arnold.

Grimshaw, J. (1991) Extended Projection. Manuscript, Brandeis University, Rutgers University.

Hale, Kenneth and Elisabeth Selkirk (1987) Government and Tonal Phrasing in Papago. Phonology 4, 151-184.

Hayes, Bruce (1989) The prosodic hierarchy in meter, in P. Kiparsky and G. Youmans (eds.) Rhythm and Meter, 201-260. Phonetics and Phonology, 1. Academic Press, New York.

Hayes, Bruce (1989) Compensatory lengthening in moraic phonology. Linguistic Inquiry 20, 253-306.

Hayes, Bruce (1991) Metrical stress theory: Principles and case studies. Draft manuscript, UCLA. 
Hyman, L. (1987) Prosodic domains in Kukuya. Natural Language and Linguistic Theory 5, 311-334.

Hyman, L. (1988) Direct vs. indirect conditioning of phonological rules. Proceedings of ESCOL 1987, Ohio State University.

Hyman, Larry (1990) Boundary Tonology and the Prosodic Hierarchy, in S. Inkeles and D. Zec, eds., 1990, 109-126.

Inkelas, Sharon (1989) Prosodic Constituency in the Lexicon. Doctoral dissertation, Stanford University.

Inkelas, Sharon and Draga Zec (1988) Serbo-Croatian pitch accent. Language 64, 227-248.

Inkelas, Sharon and Draga Zec (eds.) (1990) The Syntax/Phonology Connection. CLSI/University of Chicago Press.

Itô, Junko and Armin Mester (1992) Weak layering and word binarity. To appear in Linguistic Jackendoff, Ray (1977) X-bar Syntax. MIT Press, Cambridge, Mass.

Jones, Daniel (1964) Outline of English Phonetics. 9th ed. Cambridge: Heffer.

Kager, R.W.J. (1989) A Metrical Theory of Stress and Destressing in English and Dutch (Eeen metrische theorie over klemtoon en klemtoonverlies in het Engels en het Nederlands). Dordrecht: ICG.

Kager, R.W.J. (1993) Alternatives to the Iambic-Trochaic Law. Natural Language and Linguistic Theory 11(2).

Kaisse, E. (1985) Connected Speech. Academic Press, New York. Kanerva, Jonni (1989) Focus and Phrasing in Chichewa Phonology. Ph.D. dissertation, Stanford University. Kanerva, Jonni (1990) Focusing on phonological phrases in Chichewa, in S. 
Inkeles and D. Zec (eds.), 1990, 145-162.

Kang, Ongmi (1992) Word internal prosodic words in Korean. Proceedings of $\quad$ Northeast Lingustic

Kang, Ongmi (1992) Korean Prosodic Morphology. Ph.D. dissertation, University of Washington.

Kidima, Lukowa (1991) Tone and Accent in Kiyaka. Ph.D. dissertation, UCLA.

Klavans, J. (1985) The independence of syntax and phonology in cliticization. Language 61, 95-120.

Ladd, D. Robert (1980) The Structure of Intonational Meaning. Bloomington, Indiana: Indiana University Press.

Ladd, D. Robert (1986) Intonational phrasing: The case for recursive prosodic structure. Phonology 3, 311-340.

Ladd, D. Robert (1992) Compound prosodic domains. Occasional Paper, Linguistics Department, University of Edinburgh.

Lehiste, Ilse and Pavle Ivi_(1986) Word and Sentence Prosody in SerboCroatian. MIT Press, Cambridge, Mass.

Liberman, Mark (1975) The Intonational System of English. Ph.D. dissertation, MIT. Published by Garland, New York, 1979.

Lin, Jo-Wang (1993) Lexical government and prosodic domains. Unpublished manuscript, University of Massachusetts/Amherst.

McCarthy, John (1991) Synchronic rule inversion. In L.A. Sutton, C. Johnson, and R. Shields, eds., Proceedings of the 17th Annual Meeting of the Berkeley Linguistics Society, pp. 192-207. Berkeley: Berkeley Linguistics Society.

McCarthy, John (1993) A case of surface constraint violation. Canadian Journal of Linguistics/Revue canadienne de linguistique 38(2), 169-195. 
McCarthy, John and Alan Prince (1986) Prosodic morphology. Unpublished manuscript, University of Massachusetts, Amherst.

McCarthy, John and Alan Prince (1991) Prosodic minimality. Lecture presented at University of Illinois conference The Organization of Phonology.

McCarthy, John and Alan Prince (1993a) Prosodic Morphology I: Constraint Interaction and Satisfaction. MIT Press, Cambridge, Mass. (To appear)

McCarthy, John and Alan Prince (1993b) Generalized Alignment. In G. Booij and J. van Marle, ed McHugh, Brian (1990) Cyclicity in the Phrasal Phonology of Kivunjo Chaga. Ph.D. dissertation, UCLA.

Mester, Armin (1994) The Quantitative Trochee in Latin. Natural Language and Linguistic Theory 12(1), 1-61.

Myers, Scott (1987) Tone and the Structure of Words in Shona. Ph.D. dissertation, University of Massachusetts, Amherst.

Nespor, Marina (1993) The phonology of clitic groups. In L. Hellan and H. van Riemsdijk, eds., Clitic Doubling and Clitic Groups. Eurotyp Working Papers, 1993, 67-90.

Nespor, Marina and Irene Vogel (1982) Prosodic domains of external sandhi rules. In H. van der Hulst and N. Smith, eds., The Structure of Phonological Representations Part I, 225-256. Dordrecht: Foris.

Nespor, Marina and Irene Vogel (1986) Prosodic Phonology. Dordrecht: Foris. Neijt, Anneke (1985) Clitics in arboreal phonology. In H. van der Hulst and N. Smith, eds., Advances in Nonlinear Phonology. Foris: Dordrecht. Pierrehumbert, Janet (1980) The Phonetics and Phonology of English Intonation. Doctoral dissertation, MIT; distributed by IULC. 
Pierrehumbert, Janet (1993) Alignment and prosodic heads. To appear in ESCOL proceedings.

Pierrehumbert, Janet and Mary Beckman (1988) Japanese Tone Structure. Cambridge, Mass: MIT Press.

Pollock, J.-Y. (1989) Verb movement, universal grammar, and the structure of IP, Linguistic Inquiry, 20.3.

Prince, Alan and Paul Smolensky (1993) Optimality Theory: Constraint Interaction in Generative Grammar, MIT Press, Cambridge, Mass. (To Phonology 4, 37-60.

Rice, Keren (1991) Word-internal prosodic words in Slave. Manuscript, University of Toronto.

Selkirk, Elisabeth O. (1972) The Phrasal Phonology of English and French. Ph.D. dissertation, MIT.

Selkirk, Elisabeth O. (1978/81) On prosodic structure and its relation to syntactic structure, in T. Fretheim, ed., Nordic Prosody II. Trondheim: Tapir, 111-140.

Selkirk, Elisabeth O. (1980) The role of prosodic categories in English word stress. Linguistic Inquiry 11, 563-605.

Selkirk, Elisabeth O. (1981) On the nature of phonological representation, in J. Anderson, J. Laver and T. Meyers, eds., The Cognitive Representation of Speech, Amsterdam: North Holland.

Selkirk, Elisabeth O. (1984) Phonology and Syntax: The Relation Between Sound and Structure. Cambridge: MIT Press.

Selkirk, Elisabeth O. (1986) On derived domains in sentence phonology. 
Phonology 3, 371-405.

Selkirk, Elisabeth O. (1989) Parameterization in the syntax-phonology mapping:

The case of Chinese dialects. Paper presented at the 12th GLOW

Colloquium, Utrecht.

Selkirk, Elisabeth O. (1993a) Constraints on prosodic structure -- A modular approach. Paper presented at ESCA Workshop on Prosody, Lund University, September 1993.

Selkirk, Elisabeth O. and Koichi Tateishi (1988) Minor phrase formation in Japanese. CLS 24, 316-336.

Selkirk, Elisabeth O. and Tong Shen (1990) Prosodic domains in Shanghai Chinese, in S. Inkeles and D. Zec, eds., 1990, 313-338.

Selkirk, Elisabeth O. and Koichi Tateishi (1991) Syntax and downstep in Japanese, in C. Georgopoulos and R. Ishihara, eds., Interdisciplinary Approaches to Language: Essays in Honor of S.-Y. Kuroda, 519-544, Kluwer: Dordrecht.

Shattuck-Hufnagel, S., M. Ostendorf, and K. Ross (1994) Stress shift and early pitch accent placement in American English words. To appear in Journal of Phonetics.

Sweet, Henry (1891) A Handbook of Phonetics. Oxford: Henry Frowde.

Sweet, Henry (1908) The Sounds of English -- An Introduction to Phonetics. Oxford: Clarendon Press.

Tesar, B. and P. Smolensky (1993) The learning of optimality theory: An algorithm and some basic complexity results. CU-CS-678-93, October 1993. Department of Computer Science, University of Colorado at Boulder. Vogel, Irene (1988) The clitic group as a constituent in prosodic phonology. 
Paper presented at LSA Meeting, New Orleans, December 1988.

Zec, Draga (1988) Sonority Constraints on Prosodic Structure. Ph.D. dissertation, Stanford University.

Zec, Draga (1993a) Rule domains and phonological change. In S. Hargus and E. Kaisse, eds., Stuc

Zec, Draga (1994) Footed tones and tonal feet: Rhythmic constituency in a pitch accent language. Manuscript, Cornell University.

Zwicky, Arnold (1970) Auxiliary reduction in English. Linguistic Inquiry 1, 323-336.

Zwicky, Arnold (1977) On Clitics. IULC, Bloomington, Indiana. 